\title{
Effect of Core Architecture on Charpy Impact and Compression Properties of Tufted Sandwich Structural Composites
}

\author{
Chen Chen ${ }^{1}$, Peng Wang ${ }^{2, *}$ and Xavier Legrand ${ }^{1}$ \\ 1 University of Lille, Ensait, Gemtex, F-59000 Roubaix, France; chen.chen@ensait.fr (C.C.); \\ xavier.legrand@ensait.fr (X.L.) \\ 2 University of Haute-Alsace, Ensisa, Lpmt, F-68000 Mulhouse, France \\ * Correspondence: peng.wang@uha.fr; Tel.: +33-3-89-33-66-48; Fax: +33-3-89-33-63-39
}

Citation: Chen, C.; Wang, P.;

Legrand, X. Effect of Core

Architecture on Charpy Impact and

Compression Properties of Tufted

Sandwich Structural Composites.

Polymers 2021, 13, 1665. https://

doi.org/10.3390/polym13101665

Academic Editor: Francisco

Javier Espinach Orús

Received: 26 April 2021

Accepted: 17 May 2021

Published: 20 May 2021

Publisher's Note: MDPI stays neutral with regard to jurisdictional claims in published maps and institutional affiliations.

\begin{abstract}
This study presents a novel sandwich structure that replaces the polypropylene (PP) foam core with a carbon fiber non-woven material in the tufting process and the liquid resin infusion (LRI) process. An experimental investigation was conducted into the flatwise compression properties and Charpy impact resistance of sandwich composites. The obtained results validate an enhancement to the mechanical properties due to the non-woven core and tufting yarns. Compared to samples with a pure foam core and samples without tufting threads, the compressive strength increased by $45 \%$ and $86 \%$, respectively. The sample with a non-woven layer and tufting yarns had the highest Charpy absorbed energy $\left(23.85 \mathrm{Kj} / \mathrm{m}^{2}\right)$, which is approximately $66 \%$ higher than the samples without a non-woven layer and $90 \%$ higher than the samples without tufting yarns. Due to the buckling of the resin cylinders in the Z-direction that occurred in all of the different sandwich samples during the compression test, the classical buckling theory was adopted to analyze the differences between the results. The specific properties of the weight gains are discussed in this paper. The results show that the core layers have a negative effect on impact resistance. Nevertheless, the addition of tufting yarns presents an obvious benefit to all of the specific properties.
\end{abstract}

Keywords: textile composites; sandwich; tufting; compression; Charpy impact

\section{Introduction}

Sandwich composites normally consist of two face sheets with high in-plane mechanical properties and a lightweight core that undergoes shear loading and through-thethickness (TT) compressive loading. They are applied in many industries, such as the construction, automotive, military, and aerospace industries, due to their advantage in weight saving [1]. At the request of being light-weight, a conventional sandwich usually uses polymer foam as the core material [2]. However, a sandwich with low-density core materials usually presents weaknesses in the TT direction, including low impact resistance and low flatwise compressive strength [3]. In addition, a common problem of the sandwich structure is the delamination between face sheets and core materials [4].

Therefore, it is necessary to improve the capacity to bear TT loading. The most common method is inserting a TT reinforcement, which can be achieved with Z-pins [5-9], 3D weaving [10-12], stitching [13-15], and tufting [16-18]. Additionally, a TT reinforcement can augment shear resistance to prevent delamination [13]. Some studies present experimental and modeling investigations on a 3D sandwich. Che et al. compared the compression performance of an octahedrally stitched sandwich composite with a sandwich that had cellular core materials [19]. May-Pat et al. used the conventional relations of equivalent series-parallel springs to estimate the compressive and shear properties of sandwiches and analyzed the weight gain caused by the massive absorbed resin [20]. Jijun et al. [21] fabricated a novel X-Truss / foam sandwich structure with Z-pins inserted and bias stitching, and the compression test was conducted to evaluate these two methods. The results indicated that the specimens made from the Z-pin process have a higher compression modulus 
compared to those made with bias stitching. The mechanical properties of a foam core with perforations and stitching were investigated by Yalkin et al. [22], and they found that the newly proposed stitched core specimens with a relatively insignificant weight increase have superior mechanical performance compared to plain core specimens. Daowu analyzed the effects of the initial curvature and the angle of inclination of core fibers on the TT elastic moduli and compressive strength of the fibrous core [23]. Long et al. investigated the influence of the sandwich thickness, TT fiber density, and other parameters on compression behavior [24]. Cartié and Fleck modeled the buckling load and compressive strength of Z-pins [25]. Mouritz and Nanayakkara improved the calculation model of compressive strength and modulus based on these studies [2,3]. Nishi et al. [26] investigated the Charpy impact property of sandwiches with a polycarbonate core. Srivastava analyzed the impact behaviors of sandwiches with a polyurethane foam core and E-glass fiber face sheets with the Charpy impact test, the Izod impact test, and the weight drop test [27].

However, the research objects of these works are usually a sandwich structure with a pure foam core; different core materials are not considered. Changing the design and raw materials of the core construction can affect both the compressive and impact properties of the sandwich composite [28]. In addition to TT reinforcement, another method to improve load capacity is to adopt core materials with higher mechanical properties. Non-woven fabrics are considered a potential replacement.

The originality of this study is the introduction of both non-woven core material and TT tufting yarns in a sandwich structure to improve its mechanical performance. The influence of these two reinforcements is determined using compression and Charpy impact experimental investigation.

\section{Materials and Methods}

\subsection{Process of Sandwich Composite Manufacturing}

To insert the reinforcements in Z-direction, a tufting needle with yarn inside punctured the superposed layers. The yarn was retained within the preform when the needle retracted (see Figure 1). After the sandwich preform was produced, it could be impregnated using the LRI process, where the voids in an evacuated preform were filled with a liquid epoxy resin. When the resin solidified, the solid resin bound all the raw materials of the sandwich into a unified rigid composite.

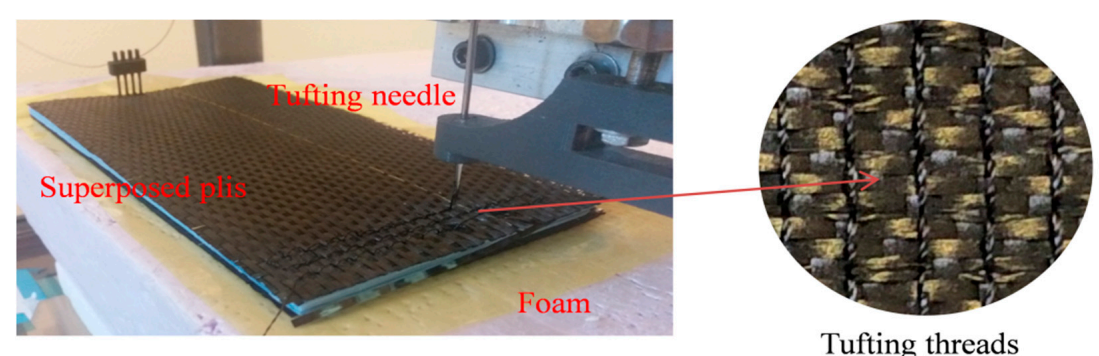

(a) Tufted sandwich preform

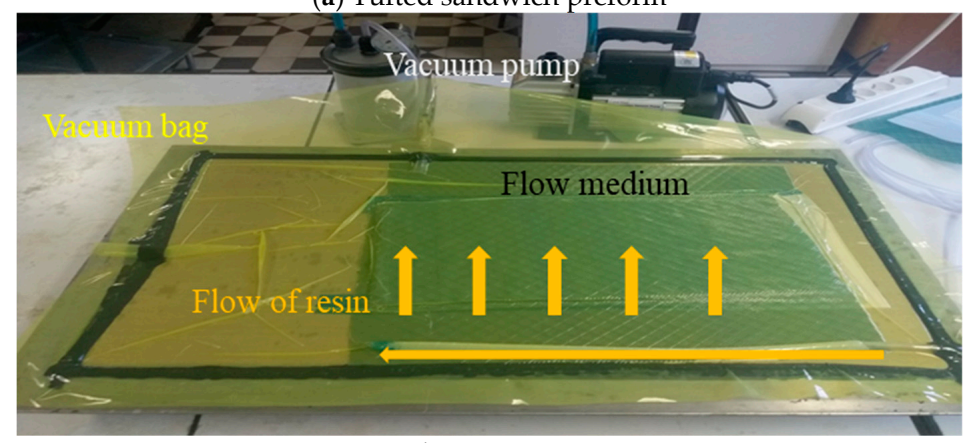

(b) LRI stage

Figure 1. Manufacturing process of the sandwich composite. 
Four groups with different core architectures were prepared (shown in Table 1). The sandwich core could be divided into two parts: the TT resin cylinders parallel to the $\mathrm{Z}$-direction and the core layers normal to the Z-direction. All of the sample sets were reinforced by tufting with yarns except $\mathrm{SW}-4$, which was punctured by a needle without yarn. As a result, the TT column of SW-4 was pure resin, while the columns of the other groups consisted of carbon fiber and resin. The superposed core layers of SW-1 were the same as SW-2: three plies of foam. The difference was that the foam of SW-2 was later removed, leaving only the columns connected by the two skins. In SW-3 and SW-4, the central foam layer was replaced by a non-woven mat (see Figure 2).

Table 1. Essential parameters of the samples.

\begin{tabular}{cccc}
\hline Sample ID & Core Material & TT Reinforcement & Thickness (mm) \\
\hline SW-1 & 3 layers of foam & & $7.27 \pm 0.29$ \\
SW-2 & Hollow & Yarn/resin cylinders & $6.75 \pm 0.16$ \\
SW-3 & Foam/Non-woven & Pure resin cylinders & $6.58 \pm 0.17$ \\
SW-4 & & T.46 \pm 0.15 \\
\hline
\end{tabular}

SW-1

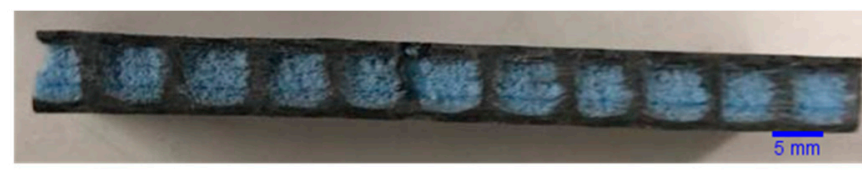

SW-2

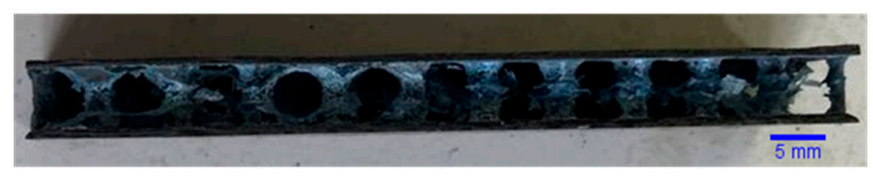

SW-3

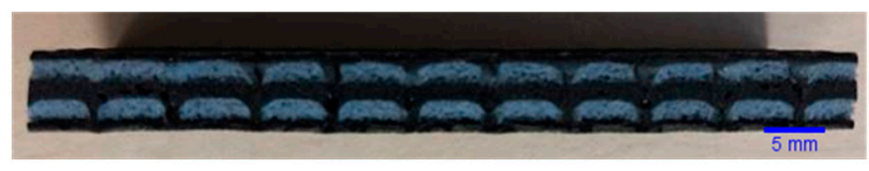

SW-4

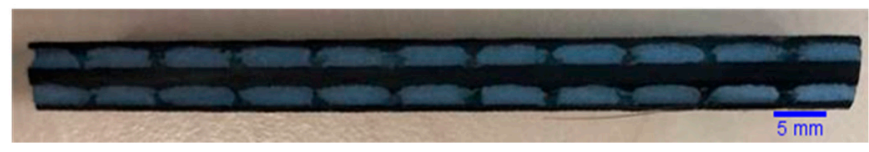

Figure 2. Photos of different sandwich structures.

The basic information about the raw textile materials, the foam, and the resin are presented in Table 2.

Table 2. Parameters of the raw materials.

\begin{tabular}{cccc}
\hline Raw Materials & Weight Parameter & $\begin{array}{c}\text { Young's Modulus } \\
\text { (GPa) }\end{array}$ & Elongation at Break \\
\hline Skin fabric & $285 \mathrm{~g} / \mathrm{m}^{2}$ & 24.4 & $3.5 \%$ \\
Non-woven & $210 \mathrm{~g} / \mathrm{m}^{2}$ & 15.8 & - \\
Tufting yarn & Linear density: $2 \times 67 \mathrm{Te}$ & 240.0 & $1.7 \%$ \\
Foam & Density: $0.01 \mathrm{~g} / \mathrm{cm}^{3}$ & $1.6 \times 10^{-2}$ & $6.7 \%$ \\
Epoxy resin & Density: $1.2 \mathrm{~g} / \mathrm{cm}^{3}$ & 2.9 & $1.7 \%$ \\
\hline
\end{tabular}

\subsection{Experimental Methods}

\subsubsection{Flatwise CompressiveTtest}

To determine the compressive strength in the Z-direction, where the core would be placed, in structural construction, the test was designed according to the standard ASTM 
C365-16 [29]. The general principle of the compression tests is shown in Figure 3. The specimens were parallelepipeds with a square base with a dimension of $25 \times 25 \mathrm{~mm}^{2}$. The specimens to be tested needed to be placed exactly in the center of the head of the indenter. Each test was repeated five times to ensure high repeatability of the testing and results. The flatwise compressive strength $\left(\sigma_{z}\right)$ and its specific value $\left(\sigma_{z s}\right)$ are given by the following:

$$
\begin{gathered}
\sigma_{z}=P / b^{2} \\
\sigma_{z s}=P / \rho b^{2}
\end{gathered}
$$

where $P$ is the measured value of the load, $b$ is the width of the sample, and $\rho$ is the density of the sample. The compressive modulus $\left(E_{z}\right)$ and the specific modulus $\left(E_{z s}\right)$ are determined from the stress-strain curves obtained using the following equation:

$$
\begin{gathered}
E_{z}=\sigma_{Z} \times t / d \\
E_{z s}=\sigma_{Z} \times t / \rho d
\end{gathered}
$$

where $t$ is the thickness of the sandwich specimen and $d$ is the displacement of the moving loading plate.

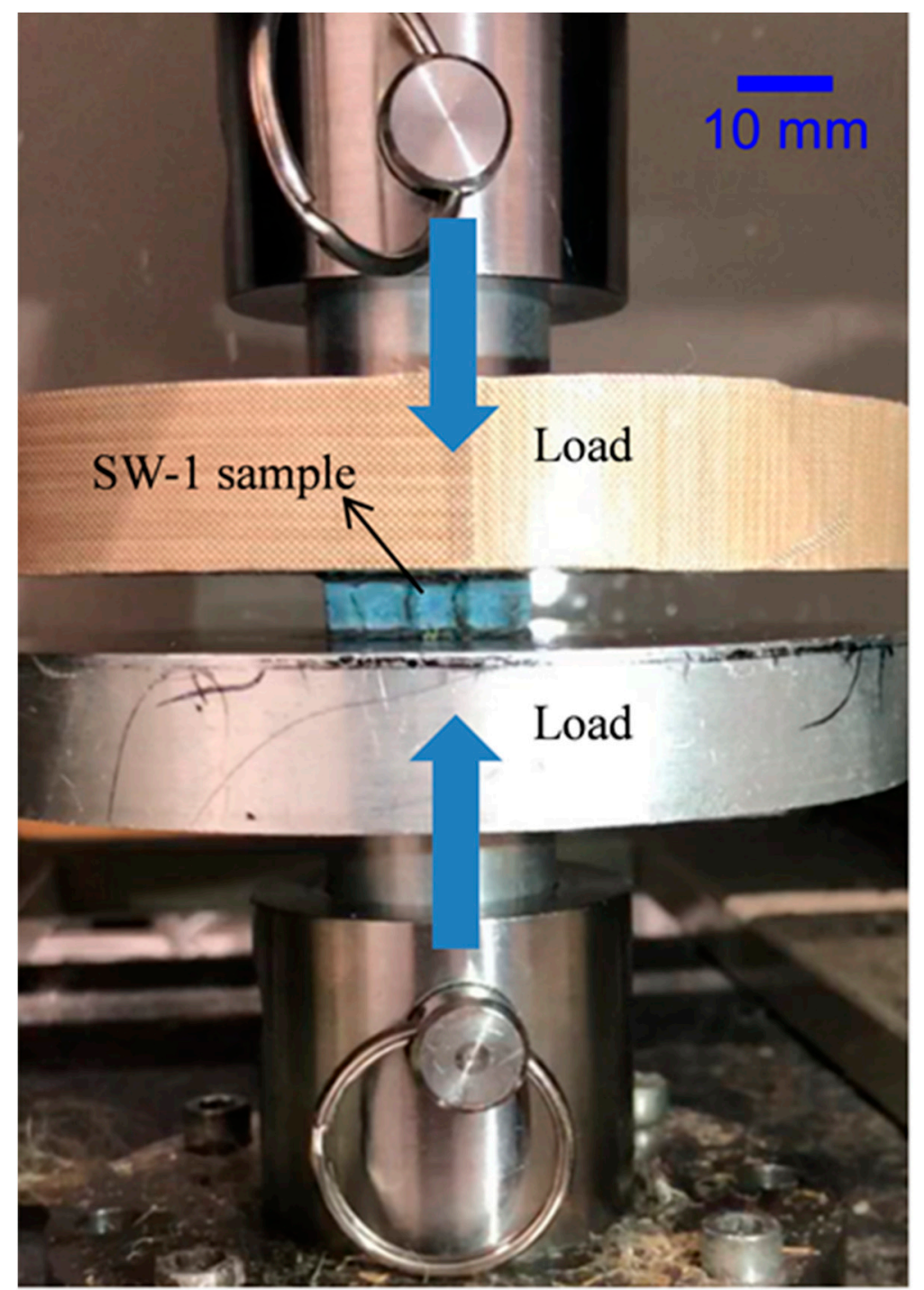

Figure 3. Compressive test device. 


\subsubsection{Charpy Impact Test}

For sandwich composites, usually, only tests in the flatwise direction are carried out. The Charpy impact strength of the composites was tested according to EN ISO 179-1 [30]. This test was designed to measure the resistance to failure of a material subjected to a suddenly applied impact. The value measured was the impact energy or the energy absorbed before fracture. The apparatus consisted of a pendulum of known mass and length that was dropped from a known height in order to impact a notched specimen of material. The energy transferred to the material could be inferred by comparing the difference in height of the hammer before and after the fracture (energy absorbed by the fracture event, see Figure 4$)$, which is denoted by $W$. The length $(l)$ and width $(b)$ of the specimens were $80 \mathrm{~mm}$ and $10 \mathrm{~mm}$, respectively. The resilience $(K)$ can be computed by the following:

$$
K=W / l b
$$

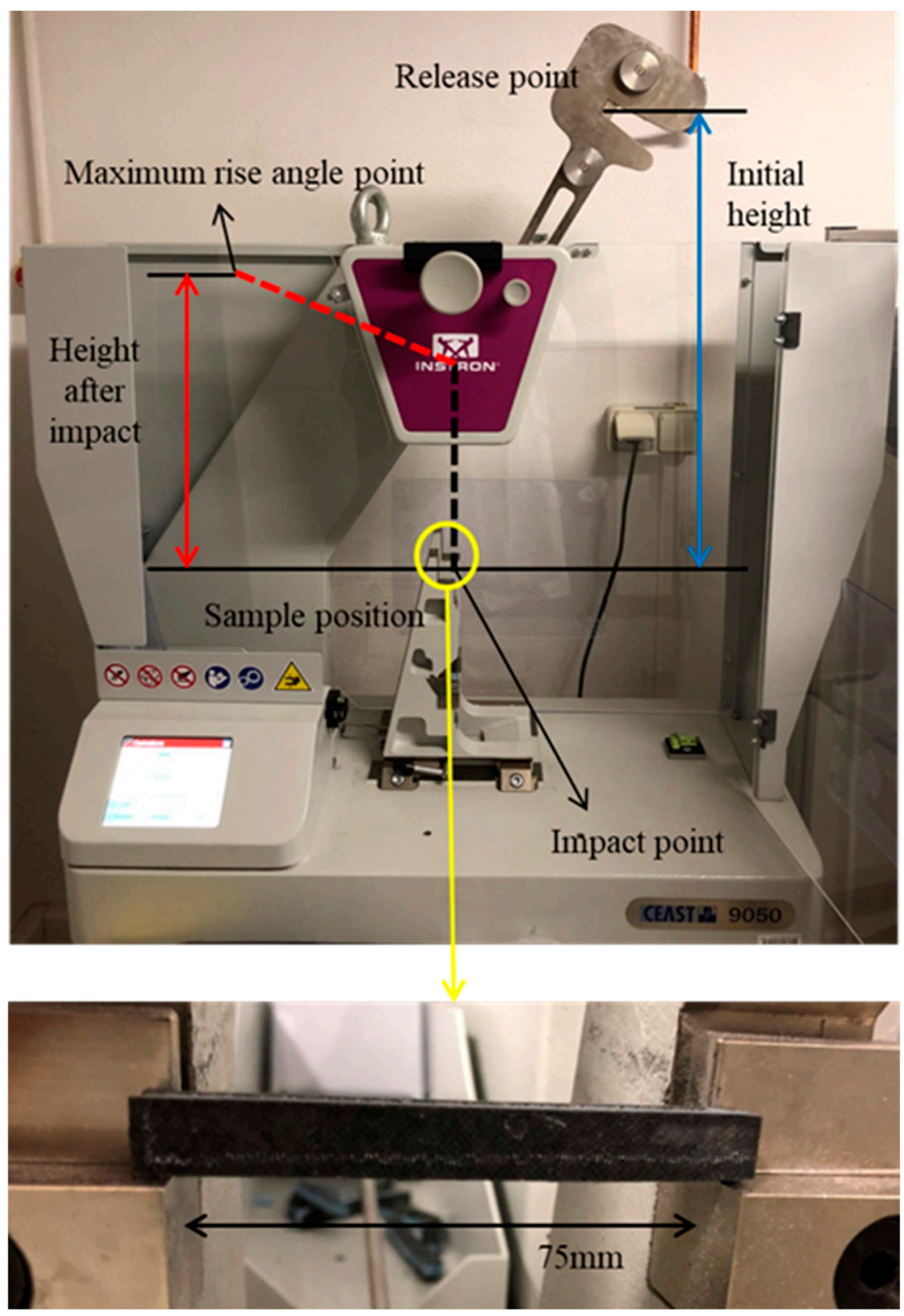

Figure 4. Charpy impact test schematization. 
Considering the mass of samples, the specific resilience is denoted by $K_{S}$ and is determined by the following:

$$
K_{s}=K / \rho
$$

\section{Results}

\subsection{Compression}

The effects of the core materials and the tufting yarns on the resistance to flatwise compression loading are shown in Figure 5. The compressive stress-strain curves of the sandwich samples with four different cores are presented. The curves show an initial elastic stage in which the slope represents the compressive modulus. The maximum stress values before failure of the samples are arranged in descending order: 6.40 MPa in SW-3, 4.42 MPa in SW-1, 3.45 MPa in SW-4, and 3.24 MPa in SW-2 (see Table 3).

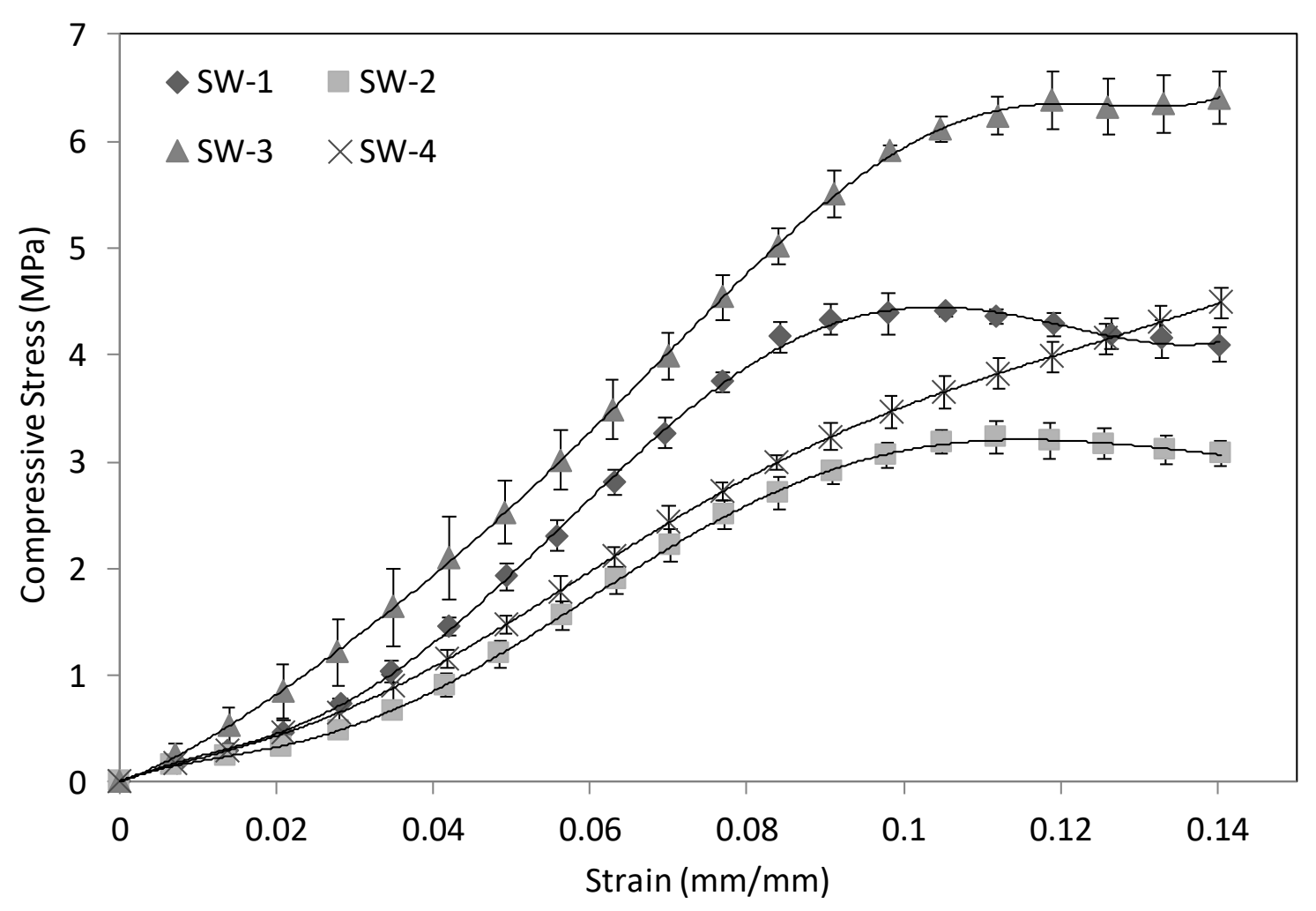

Figure 5. Flatwise compression stress-strain curves.

Table 3. Compressive properties of sandwich composites.

\begin{tabular}{cccccc}
\hline Sample ID & $\begin{array}{c}\text { Compressive } \\
\text { Strength (MPa) }\end{array}$ & $\begin{array}{c}\text { Specific Compressive } \\
\text { Strength (kN.m/kg) }\end{array}$ & $\begin{array}{c}\text { CV } \\
\text { (Coefficient of } \\
\text { Variation) }\end{array}$ & $\begin{array}{c}\text { Compressive } \\
\text { Modulus } \\
\text { (MPa) }\end{array}$ & $\begin{array}{c}\text { Specific Compressive } \\
\text { Modulus (kN·m/kg) }\end{array}$ \\
\hline SW-1 & 4.42 & 9.52 & $2.78 \%$ & 64.32 & 138.61 \\
SW-2 & 3.24 & 7.60 & $5.48 \%$ & 45.17 & 95.70 \\
SW-3 & 6.40 & 9.27 & $3.40 \%$ & 67.23 & 97.46 \\
SW-4 & 3.45 & 5.55 & $6.09 \%$ & 44.82 & 72.17 \\
\hline
\end{tabular}

The compressive load was mainly carried by the core materials; thus, the analysis of the skins does not have any importance. After the first peak stress, the resin columns buckled or fractured and stress began to decrease. However, the core layers resisted the compression and increased the stress as the compression proceeded because of densification [3,31]. Thus, only the structural failure phase (the first peak stress) was analyzed. The behavior of a sandwich tufted with yarns (SW-1, SW-2, and SW-3) was different from that of a sandwich 
without tufting threads (SW-4). The curves of SW-1, SW-2, and SW-3 show a small drop following the ultimate compression stress due to the breaking of the composite columns. On the contrary, the stress value of SW-4 has no downward trend after the failure point and keeps increasing, and only the slope becomes smaller. Although SW-3 generally experienced a larger load drop than SW-4 following the failure point, SW-3 presented a higher compressive load-bearing capacity in the entire strain range. The profits from the yarns in Z-direction is clear compared to the sandwich panels with no tufting threads, which can be explained by comparing Equations (11) and (12). The difference is determined by the modulus and the volume fraction in the TT columns with tufting yarns.

The effects of the foam core on the ultimate stress until failure and the compressive modulus can be obtained by comparing SW-1 and SW-2. The stress value and the slope of SW-1 are higher, which indicates that compressive strength and modulus increase with the presence of a foam core. The columns in the Z-direction and the core layers (foam or foam/non-woven) carry the compressive load together. Nevertheless, by using Equations (9)-(11) and (13), it can be seen that the increases in the stress value of nonwoven materials are higher than those of pure foam.

Considering the weight increase caused by the non-woven layer, the comparison of specific stress is more significant. The results in Table 3 show that SW-1 and SW-3 have higher values, which are 9.52 MPa and 9.27 MPa, respectively. These two values are very close. Taking into account the coefficient of variation, it can be considered that the specific compressive properties of these two groups are the same. The reason for the increase in mass is that the higher porosity and hygroscopicity of the non-woven material itself causes the absorption of excessive resin [32,33].

Though the external observation of the failure mode was not carried out during the compression process due to either the foam or non-woven materials covering the deformation of the columns in the core, the fracture of the columns was confirmed after the test. These ruptures occurred near the junctions between the skin and the columns. The foam was critically flattened, and it could not recover its original thickness, but the non-woven core remained the same as it had been initially. The bulking and the cracking of the foam and the breaking of the columns are the principal failure modes. The longitudinal splitting of the columns under the compressive load followed by its deformation caused the foam to crack and collapse, which led to a large loss of the entire core's rigidity.

In the case of SW-2, only the fiber/resin columns underwent compressive loading. Thus, the failure mode is the buckling of the columns, and the failure load $\left(F_{s w 2}\right)$ was reached when the columns reached their critical buckling load.

$$
F_{s w 2}=\pi^{2} E_{c o l} I /(K t)^{2}
$$

where $E_{c o l}$ is the elastic modulus of columns, $I$ is the area moment of inertia, and $K$ is the column effective length factor that depends on the conditions of the end support of the column. As both ends of the column are considered fixed, the value of $K$ is 1 in this paper. Consequently, the equation of the column's compressive strength that fails by buckling can be presented as follows:

$$
\sigma_{c o l}=\pi^{2} r^{2} E_{c o l} / 4 t^{2}
$$

where $r$ is the radius of the TT columns. The compressive stress $\left(\sigma_{z}\right)$ can be predicted by the following:

$$
\begin{gathered}
\sigma_{z}^{s w 1}=\pi^{2} r^{2} E_{c o l} v_{c o l} / 4 t^{2}+E_{f} \varepsilon v_{f} \\
\sigma_{z}^{s w 2}=\pi^{2} r^{2} E_{c o l} v_{c o l} / 4 t^{2} \\
\sigma_{z}^{s w 3}=\pi^{2} r^{2} E_{c o l} v_{c o l} / 4(K t)^{2}+E_{c} \varepsilon\left(1-v_{c o l}\right) \\
\sigma_{z}^{s w 4}=\pi^{2} r^{2} E_{r} v_{c o l} / 4(K t)^{2}+E_{c} \varepsilon\left(1-v_{c o l}\right)
\end{gathered}
$$

where the superscripts $s w 1, s w 2, s w 3$, and $s w 4$ represent the four different groups; $\varepsilon$ is the compressive strain; $E$ is Young's modulus; and the subscripts $r$ and $f$ represent the resin 
and the foam, respectively. Young's modulus of the core with non-woven layers $\left(E_{c}\right)$ is obtained by using the following [20]:

$$
E_{c}=\left(2 c_{f}+c_{n}\right) E_{f} E_{n} /\left(2 c_{f} E_{n}+c_{n} E_{f}\right)
$$

where $c$ is the thickness and the subscripts $n$ represent the non-woven material (see Figure 6).

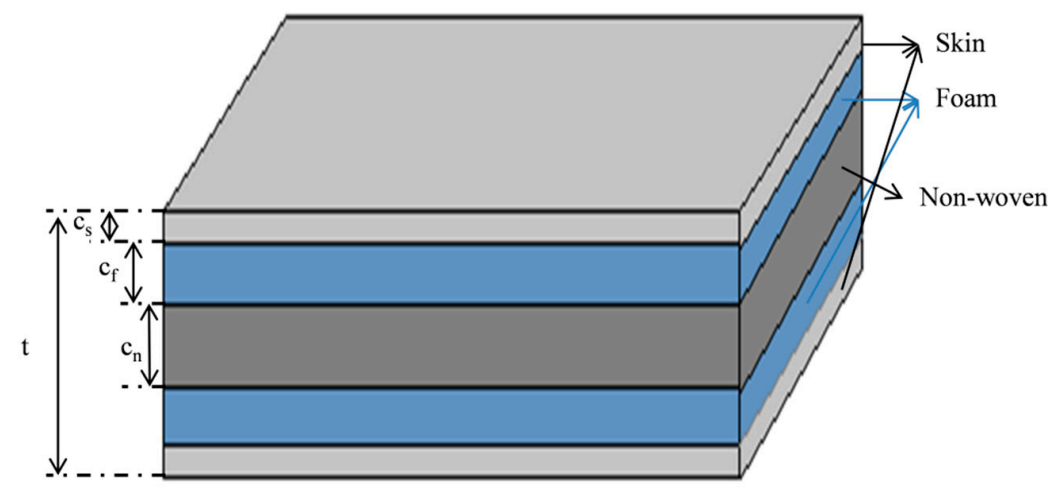

Figure 6. Schematic for calculation of the SW-3 and SW-4 samples.

\subsection{Charpy Impact}

The results of the Charpy absorbed energy $\left(\mathrm{Kj} / \mathrm{m}^{2}\right)$ of each group are presented in Figure 7. SW-3 has the highest impact strength $\left(23.85 \mathrm{Kj} / \mathrm{m}^{2}\right)$ among these four groups of samples. PP foam has a low fracture toughness; it promoted the extension of cracks from the top skin to the bottom skin by connecting these two skins. This resulted in a rupture of both skins (as shown in Figure 8) and a lower absorbed impact energy. Compared with the hollow structure (SW-2), the presence of the foam core (SW-1) increased the brittleness of the core. The absorbed energy of SW-3 is approximately $66 \%$ higher than that of SW-1 $\left(14.38 \mathrm{Kj} / \mathrm{m}^{2}\right)$. Pure epoxy resin and carbon fiber are normally considered brittle materials [34]. However, toughness is related to both strength and brittleness. The tensile strength and elongation at the break of the resin-infused non-woven composite were measured as $63.79 \mathrm{MPa}$ and $1.49 \%$, respectively. Compared with the parameters the of foam (1.02 MPa and 6.7\%), it can be obtained that the non-woven composite layer has a higher toughness. This can contribute to improving the toughness of the whole sandwich structure. Moreover, the higher absorbed energy of the fiber/resin columns compared with the pure resin columns (SW-4) can be explained by the same mechanism.

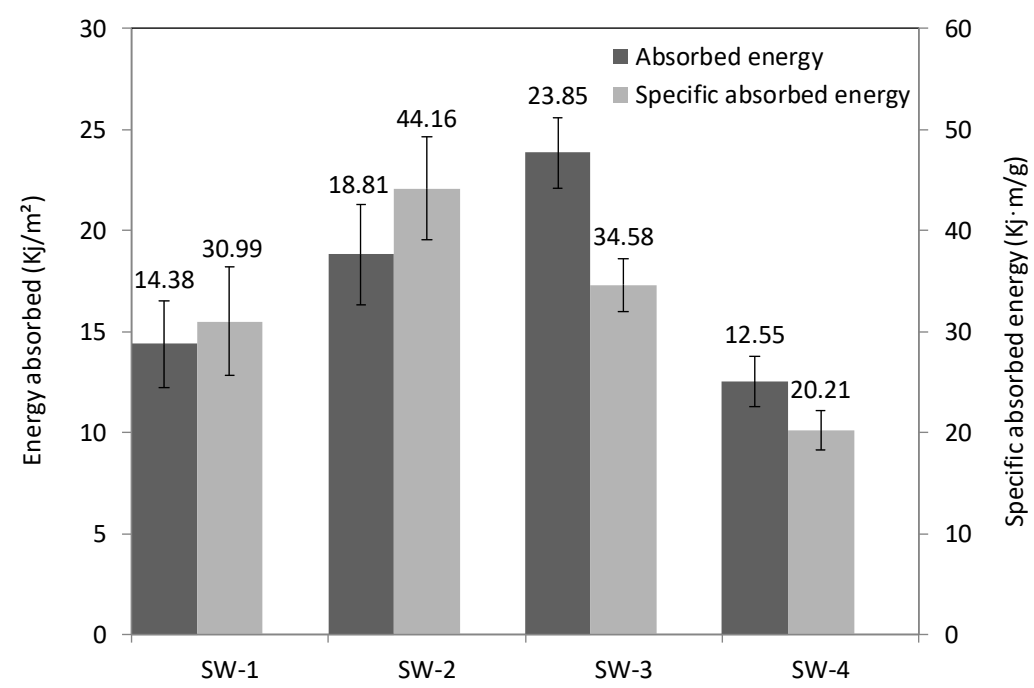

Figure 7. Impact energy absorbed during the Charpy test. 
SW-1

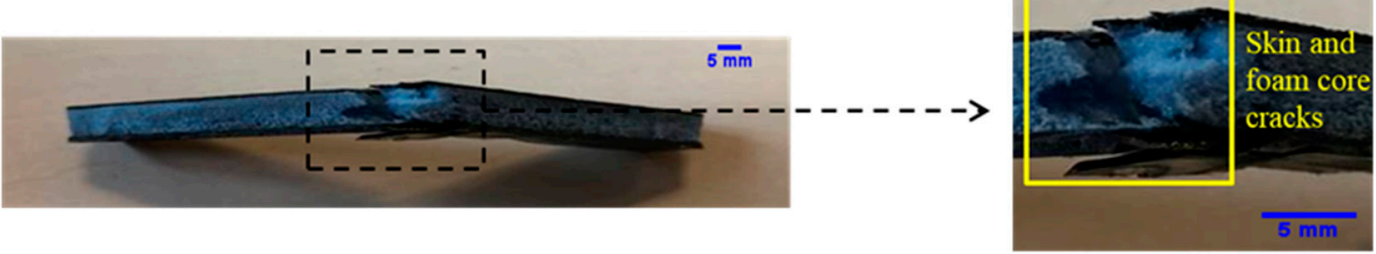

SW-2

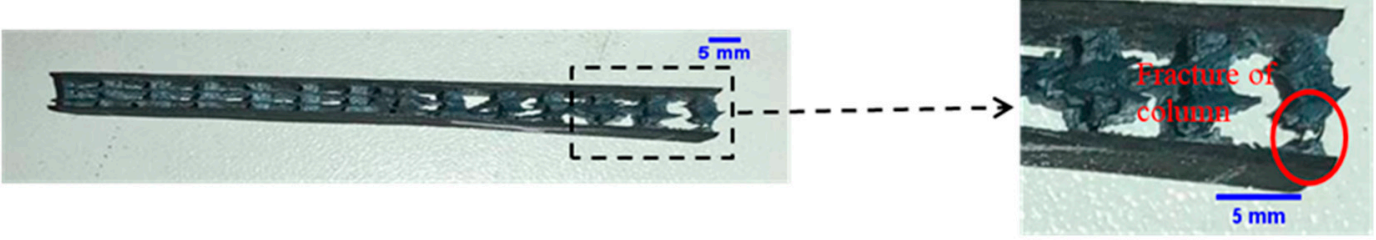

SW-3

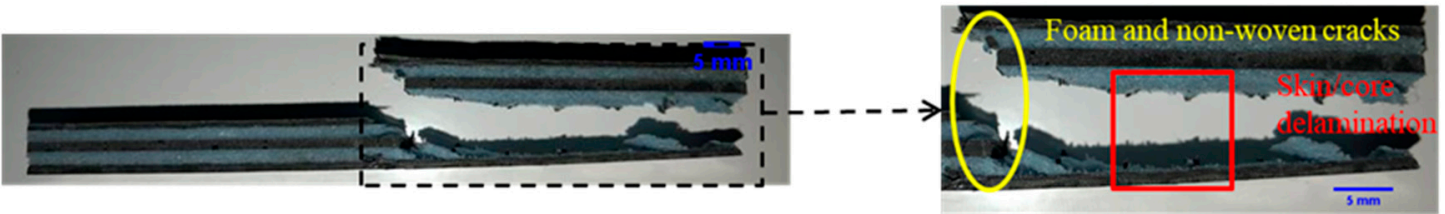

SW-4
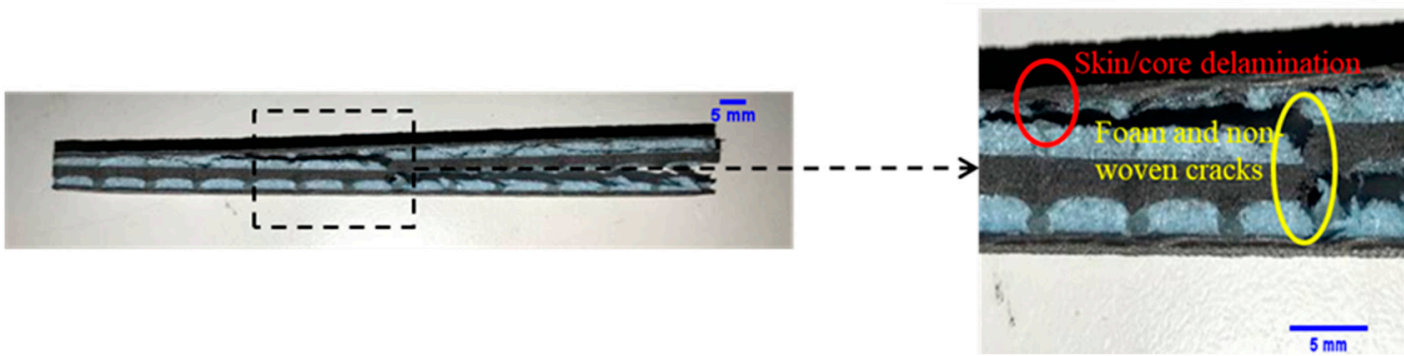

Figure 8. Fractured specimens after the Charpy impact test.

Although the presence of carbon fiber materials can increase the absorbed energy, it also increases the whole sandwich mass, which goes against the lightweight design trend. Thus, the introduction of the notion of specific absorbed energy is significant. The results indicate that the SW-2 with a hollow structure presents the largest value, as it is the lightest, and that it has a relatively high absorbed energy.

The photographs of the fractured samples of each set are presented in Figure 8 . A brittle fracture tendency can be seen in the sandwich with core layers (SW-1, SW-3, and SW-4) by visual analysis, which shows more serious damage to the core structure. The delamination between the core and the skin can be observed in all of the sandwich groups except SW-1, and the cracks of the foam and non-woven layer are determined. The fracturing of the columns mainly occurred at the connection points between the columns and the composite layers (the fabric skin and the non-woven core ply), which is the weak zone of the columns' mechanical property.

\section{Conclusions}

Tufting yarn in the Z-direction and the non-woven core layer can effectively improve flatwise compressive properties and Charpy impact tenacity by increasing the compression modulus, strength, and absorbed strain energy capacity. The ultimate compressive strength is determined by the elastic modulus of the TT columns, both foam and non-woven. In addition, the volume fraction of the columns and non-woven material also plays an important role. The columns' reinforcements failed due to buckling. However, the specific impact properties were not positively influenced by the presence of tufting yarn and non-woven material. The increase in the sample weight by adding foam or non-woven material is more significant compared to improved absorbed energy, which results in a lower specific impact property. 
The manufacturing process and the sandwich core structure do not allow for an accurate calculation for the parameters of columns and the non-woven core material; hence, the existing models can only predict the mechanical property's tendency to augment or diminish. The following work needs to be conducted in the future:

1. Improvement of the manufacturing process to strictly control the resin content of the sample.

2. A new observation method to determine the status of each reinforcement and the failure mode.

3. Improvement of the calculation model to accurately determine the compressive strength and modulus.

Author Contributions: Conceptualization, C.C. and P.W.; methodology, C.C., P.W. and X.L.; validation, P.W. and X.L.; formal analysis, C.C. and P.W.; investigation, C.C.; data curation, C.C.; writing—original draft preparation, C.C.; writing—review and editing, P.W. and X.L.; visualization, C.C.; supervision, P.W. and X.L.; project administration, P.W. and X.L. All authors have read and agreed to the published version of the manuscript.

Funding: This research received no external funding.

Data Availability Statement: Not applicable.

Acknowledgments: The authors are greatly indebted to the China Scholarship Council (CSC) for providing financial support (grant number: 201808070029) to conduct this study.

Conflicts of Interest: The authors declare no conflict of interest.

\section{References}

1. Al-fatlawi, A.; Jármai, K.; Kovács, G. Optimal design of a fiber-reinforced plastic composite sandwich structure for the base plate of aircraft pallets in order to reduce weight. Polymers (Basel) 2021, 13, 834. [CrossRef]

2. Mouritz, A.P. Compression properties of z-pinned sandwich composites. J. Mater. Sci. 2006, 41, 5771-5774. [CrossRef]

3. Nanayakkara, A.; Feih, S.; Mouritz, A.P. Experimental analysis of the through-thickness compression properties of z-pinned sandwich composites. Compos. Part A Appl. Sci. Manuf. 2011, 42, 1673-1680. [CrossRef]

4. Hu, Y.; Zhu, J.; Wang, J.; Wu, Y. Interfacial Failure in Stitched Foam Sandwich Composites. Materials (Basel) 2021, 14, 2275. [CrossRef] [PubMed]

5. Du, L.; Jiao, G. Indentation study of Z-pin reinforced polymer foam core sandwich structures. Compos. Part A Appl. Sci. Manuf. 2009, 40, 822-829. [CrossRef]

6. Nanayakkara, A.; Feih, S.; Mouritz, A.P. Experimental impact damage study of a z-pinned foam core sandwich composite. J. Sandw. Struct. Mater. 2012, 14, 469-486. [CrossRef]

7. Kaya, G.; Selver, E. Impact resistance of Z-pin-reinforced sandwich composites. J. Compos. Mater. 2019, 53, 3681-3699. [CrossRef]

8. M'membe, B.; Gannon, S.; Yasaee, M.; Hallett, S.R.; Partridge, I.K. Mode II delamination resistance of composites reinforced with inclined Z-pins. Mater. Des. 2016, 94, 565-572. [CrossRef]

9. Knopp, A.; Scharr, G. Tensile Properties of Z-Pin Reinforced Laminates with Circumferentially Notched Z-Pins. J. Compos. Sci. 2020, 4, 78. [CrossRef]

10. Tekalur, S.A.; Bogdanovich, A.E.; Shukla, A. Shock loading response of sandwich panels with 3-D woven E-glass composite skins and stitched foam core. Compos. Sci. Technol. 2009, 69, 736-753. [CrossRef]

11. Mouritz, A.P.; Bannister, M.K.; Falzon, P.J.; Leong, K.H. Review of applications for advanced three-dimensional fibre textile composites. Compos. Part A Appl. Sci. Manuf. 1999, 30, 1445-1461. [CrossRef]

12. Gereke, T.; Cherif, C. A review of numerical models for 3D woven composite reinforcements. Compos. Struct. 2019, 209, 60-66. [CrossRef]

13. Lascoup, B.; Aboura, Z.; Khellil, K.; Benzeggagh, M. Prediction of out-of-plane behavior of stitched sandwich structure. Compos. Part B Eng. 2012, 43, 2915-2920. [CrossRef]

14. Lascoup, B.; Aboura, Z.; Khellil, K.; Benzeggagh, M. Homogenization of the core layer in stitched sandwich structures. Compos. Sci. Technol. 2010, 70, 350-355. [CrossRef]

15. Zheng, X.T.; Zhang, J.F.; Yang, F.; Chai, Y.N.; Li, Y. Experimental and analytical study on the mechanical behavior of stitched sandwich composite panel with a foam core. Adv. Mater. Res. 2008, 33-37, 477-482. [CrossRef]

16. Hao, S.; Wang, P.; Legrand, X.; Liu, L.; Soulat, D. Influence of the tufting pattern on the formability of tufted multi-layered preforms. Compos. Struct. 2019, 228, 111356.

17. Liu, L.S.; Zhang, T.; Wang, P.; Legrand, X.; Soulat, D. Influence of the tufting yarns on formability of tufted 3-Dimensional composite reinforcement. Compos. Part A Appl. Sci. Manuf. 2015. [CrossRef] 
18. Dell'Anno, G.; Treiber, J.W.G.; Partridge, I.K. Manufacturing of composite parts reinforced through-thickness by tufting. Robot. Comput. Integr. Manuf. 2016, 37, 262-272. [CrossRef]

19. Che, L.; Xu, G.D.; Zeng, T.; Cheng, S.; Zhou, X.W.; Yang, S.C. Compressive and shear characteristics of an octahedral stitched sandwich composite. Compos. Struct. 2014, 112, 179-187. [CrossRef]

20. May-Pat, A.; Avilés, F.; Aguilar, J. Mechanical properties of sandwich panels with perforated foam cores. J. Sandw. Struct. Mater. 2011, 13, 427-444. [CrossRef]

21. Jijun, H.; Zuoguang, Z.; Min, L.; Zhijie, S.; Yizuo, G. The influence of preparing method on novel x-truss / foam sandwich structure. J. Reinf. Plast. Compos. 2009, 28, 1553-1565. [CrossRef]

22. Yalkin, H.E.; Icten, B.M.; Alpyildiz, T. Enhanced mechanical performance of foam core sandwich composites with through the thickness reinforced core. Compos. Part B Eng. 2015, 79, 383-391. [CrossRef]

23. Zhou, D.; Stronge, W.J. Mechanical properties of fibrous core sandwich panels. Int. J. Mech. Sci. 2005, 47, 775-798. [CrossRef]

24. Long, D.; Guiqiong, J.; Tao, H. Investigation of the effect of Z-pin reinforcement on the collapse of foam-cored sandwich panels. J. Reinf. Plast. Compos. 2008, 27, 1211-1224. [CrossRef]

25. Cartié, D.D.; Fleck, N.A. The effect of pin reinforcement upon the through-thickness compressive strength of foam-cored sandwich panels. Compos. Sci. Technol. 2003, 63, 2401-2409. [CrossRef]

26. Nishi, Y.; Tsuchikura, N.; Nanba, S.; Yamamoto, T.; Faudree, M.C. Charpy impact of sandwich structural composites (CFRP/PC/CFRP) of polycarbonate (PC) cores covered with carbon fiber cross textile reinforced epoxy polymer (CFRP) thin sheets as a function of temperature. Mater. Trans. 2012, 53, 1288-1294. [CrossRef]

27. Srivastava, V.K. Impact Behaviour of Sandwich GFRP-Foam-GFRP Composites. Int. J. Compos. Mater. 2012, 2, 63-66. [CrossRef]

28. Alsubari, S.; Zuhri, M.Y.M.; Sapuan, S.M.; Ishak, M.R.; Ilyas, R.A.; Asyraf, M.R.M. Potential of natural fiber reinforced polymer composites in sandwich structures: A review on its mechanical properties. Polymers (Basel) 2021, 13, 423. [CrossRef]

29. ASTM C365-16. Standard Test Method for Flatwise Compressive Properties of Sandwich Cores; ASTM International: West Conshohocken, PA, USA, 2016.

30. ISO 179-1: 2010. Plastics-Determination of Charpy Impact Properties-Part 1: Non-Instrumented Impact Test; ISO: Geneva, Switzerland, 2010.

31. Tita, V.; Caliri, M.F. Numerical simulation of anisotropic polymeric foams. Lat. Am. J. Solids Struct. 2012, 9, 259-279. [CrossRef]

32. Mao, N.; Russell, S.J. Fibre to Fabric: Nonwoven Fabrics; Elsevier Ltd.: Amsterdam, The Netherlands, 2015 ; ISBN 9780857095619.

33. Albooyeh, A.; Eskandarzadeh, S.; Mousavi, A. Influence of different foaming conditions on the mechanical, physical, and structural properties of polypropylene foam. Mech. Adv. Compos. Struct. 2019, 6, 225-237. [CrossRef]

34. Junaedi, H.; Albahkali, E.; Baig, M.; Dawood, A.; Almajid, A. Ductile to Brittle Transition of Short Carbon Fiber-Reinforced Polypropylene Composites. Adv. Polym. Technol. 2020, 2020, 1-10. [CrossRef] 